\title{
Assessment of Awareness and Practices of Biomedical Waste Management among Health Care Professionals at a Teaching Hospital in Uttar Pradesh
}

\author{
Monika Rajani iD \\ Department of Microbiology, Mayo Institute of Medical Sciences, Barabanki - 225 001, Uttar Pradesh, India.
}

\begin{abstract}
Improper waste management practices are a serious problem that involves not only the hospital staff but society at large. To improve biomedical waste (BMW) management, it is important to evaluate the current practices in BMW management (BMWM), identify the gaps, and address them. With this backdrop, this research was done to assess the awareness of BMW management practices among the healthcare professionals in a teaching hospital. This is a hospital-based observational study with assessment of 112 doctors, 230 nurses, and 158 waste handlers. The healthcare workers (HCW) were evaluated regarding awareness, and different practices of BMWM with a self-structured questionnaire. An overall score of $\geq 50 \%$ in each section was considered satisfactory regarding awareness and practices for BMWM. Data were analyzed statistically using SPSS Ver.21 software. Regarding the awareness on various aspects of BMWM, doctors had maximum level of awareness at $68.6 \%(60.0 \%-77.2 \%)$, followed by nurses at $69.3 \%(63.3 \%-75.3 \%)$ and waste handlers at $55.9 \%(48.2 \%-63.6 \%)$. Overall

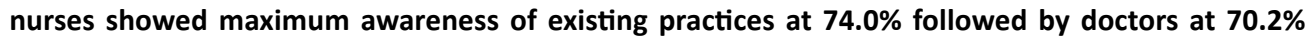
and waste handlers were at $\mathbf{5 3 . 8 \%}$. To optimize BMWM, it is important to raise awareness on best practices while evaluating the current practices. Gaps in knowledge and skills need to be identified and closed. Ongoing information, education and communication for health care professionals are pivotal in improving BMWM practices.
\end{abstract}

Keywords: Biomedical waste (BMW), Biomedical waste management (BMWM), Biomedical waste team, Infection Control, Healthcare workers (HCW)

*Correspondence: drmrajani@rediffmail.com; +91 7755091159

(Received: June 11, 2021; accepted: September 08, 2021)

Citation: Rajani M. Assessment of Awareness and Practices of Biomedical Waste Management among Health Care Professionals at a Teaching Hospital in Uttar Pradesh. J Pure Appl Microbiol. 2021;15(4):2142-2151. doi: 10.22207/JPAM.15.4.37

C The Author(s) 2021. Open Access. This article is distributed under the terms of the Creative Commons Attribution 4.0 International License which permits unrestricted use, sharing, distribution, and reproduction in any medium, provided you give appropriate credit to the original author(s) and the source, provide a link to the Creative Commons license, and indicate if changes were made. 


\section{INTRODUCTION}

Biomedical waste is the waste that is generated during investigation, treatment, or vaccination of humans or animals, or that is produced during manufacture or testing of biologicals. ${ }^{1}$ For this study it applied to the above and covers the Biomedical waste (BMW) as described in schedule - 1 of the government of India rules, 1998. About $85 \%$ of waste generation in relation to health related activities is non hazardous. The remaining $15 \%$ of waste generated out of healthcare activities is considered hazardous. These hazardous material might be infectious, toxic, or radioactive and have potential to cause injury. ${ }^{2}$ Although, the quantity of the infectious waste produced is less as compared to the overall healthcare waste, the poor waste management practices by healthcare workers lead to the mixing of the infectious waste with noninfectious waste and thereby contaminating the whole waste. ${ }^{3} \mathrm{BMW}$ waste production increased manifold during the Covid pandemic which further compounded the situation. ${ }^{4}$

Improper disposal of BMW has many adverse and harmful effects on the environment \& human health. ${ }^{5}$ High risk activities like the reuse of syringes and multi-dose vials augments the chances of blood borne diseases manyfold. ${ }^{6}$ Needles used by drug abusers lead to further spread of infection. ${ }^{7}$ Repacking of used needles/ cotton etc. can be done by unscrupulous elements. Air pollution due to incineration of improperly segregated waste produces toxic gases while water pollution is a problem due to improper liquid waste management. ${ }^{8}$ Increasing antibiotic resistance is a potential threat due to the spread of resistant strains. ${ }^{9}$

Any carelessness in the management of waste generated in a hospital tends to spread infections and contaminate the entire environment. Thus, improper waste management practices are a serious problem that involves not only the hospital staff but society at large. However, in developing countries, biomedical waste management (BMWM) have not received sufficient attention and hence it remains a major biosafety threat. ${ }^{10}$

There are numerous myths and misperceptions regarding BMWM among healthcare professionals, health administrators and the public. Lack of awareness, non- ownership, unstructured training, and lax implementation are the factors largely influencing poor BMWM in India. To improve BMWM, it is important to assess current awareness on proper BMWM. It is imperative to understand and evaluate the current practices in BMWM with gap analysis. ${ }^{11}$ With this backdrop, this research was done to assess the awareness regarding BMWM practices among the healthcare personnel in a teaching hospital. Further, suitable recommendations to improve BMW practices among healthcare personnel based on study findings were given.

The objectives of this study were to evaluate the level of awareness and existing practices regarding BMWM amongst the HCW. The study compared the level of awareness of BMWM among doctors, nursing staff, and waste handlers. Existing practices of BMWM among doctors, nursing staff, and waste handlers was also compared. Reasons behind inadequate BMWM were evaluated with a thorough assessment of the gaps in knowledge and practices among the HCWs.

\section{MATERIALS AND METHODS}

A hospital-based observational study was conducted at Career Institute of Medical Sciences and Hospital, Lucknow from October to December 2019. Ethical clearance was taken from the Institutional Ethical committee to conduct the study. Using the purposive sampling method, 500 Health Care Workers (HCWs) dealing with BMW were included for the study comprising 112 doctors, 230 nurses, and 158 waste handlers. Study groups were based on their designation as faculty, junior/senior residents, medical interns, nurses, and waste handlers. Informed consent was taken from the health care workers after explaining to them the purpose of the study. Confidentiality of the participants and data was maintained.

Our hospital has a BMWM Team that regularly conducts training programs on BMWM. The HCW were evaluated regarding awareness, and practices of biomedical waste management via a self-structured questionnaire. Question set was designed in English and then modified to the local language (Hindi) to make it easily understandable across all the classes of HCP. The questionnaire comprised twenty close-ended questions and 
was divided into two sections. The first section consisted of ten questions of one mark each and assessed the awareness regarding BMWM. The second section consisting of 10 questions included questions related to practical implications and practices. An overall score of $\geq 50 \%$ in each section was considered as the satisfactory score on awareness and practices for BMWM.

Data were analyzed statistically using SPSS Ver.21 software. Chi-square test was undertaken to find association between the HCP groups regarding their knowledge and practices towards BMWM. The $p$ value was applied on the generated data.

\section{RESULTS}

A total of $500 \mathrm{HCWs}$ participated in our study. Out of the 500, 112 (22.4\%) were doctors, $230(46 \%)$ were nurses and $158(31.6 \%)$ were waste handlers. A total of $77.8 \%$ of healthcare personnel had received training on BMWM (Table 1).

Analyzing the awareness about various aspects of BMWM, doctors had maximum level of awareness at $68.6 \%(60.0 \%-77.2 \%)$, followed by nurses at $69.3 \%(63.3 \%-75.3 \%)$ and waste handlers at $55.9 \%(48.2 \%-63.6 \%)$ (Table 2, Fig. 1).

Table 1. Health care workers who underwent BMWM Training

\begin{tabular}{lc}
\hline $\begin{array}{l}\text { HCW category } \\
(n=500)\end{array}$ & $\begin{array}{c}\text { HCW those who } \\
\text { underwent training }\end{array}$ \\
\hline Doctors (112) & $89(79.4 \%)$ \\
Nurses (230) & $191(83 \%)$ \\
Waste handlers (158) & $109(68.9 \%)$ \\
TOTAL & $389(77.8 \%)$ \\
\hline
\end{tabular}

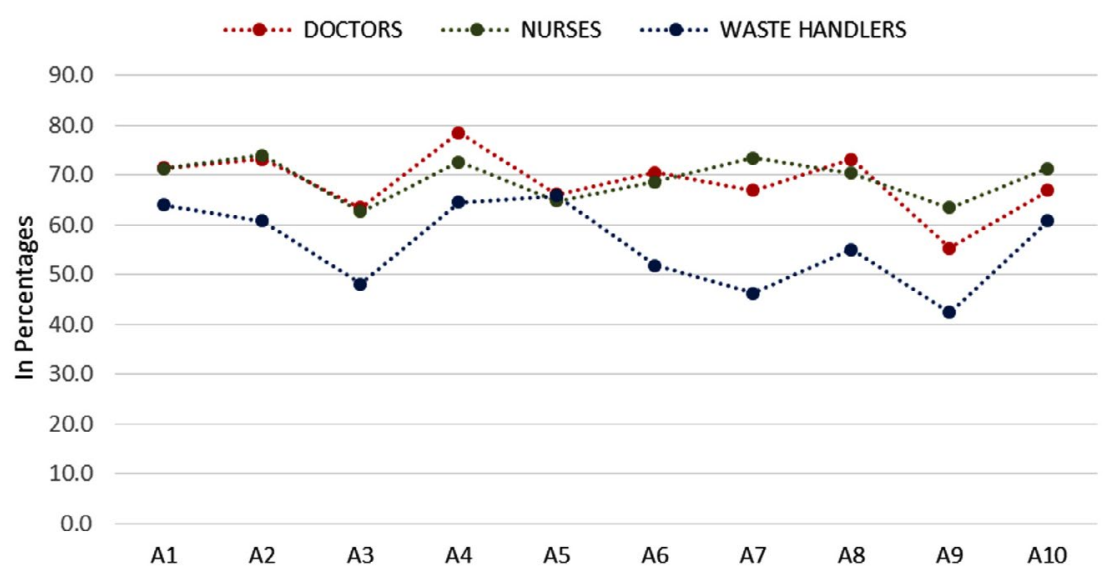

Fig. 1. Level of BMWM awareness among health care personnel.

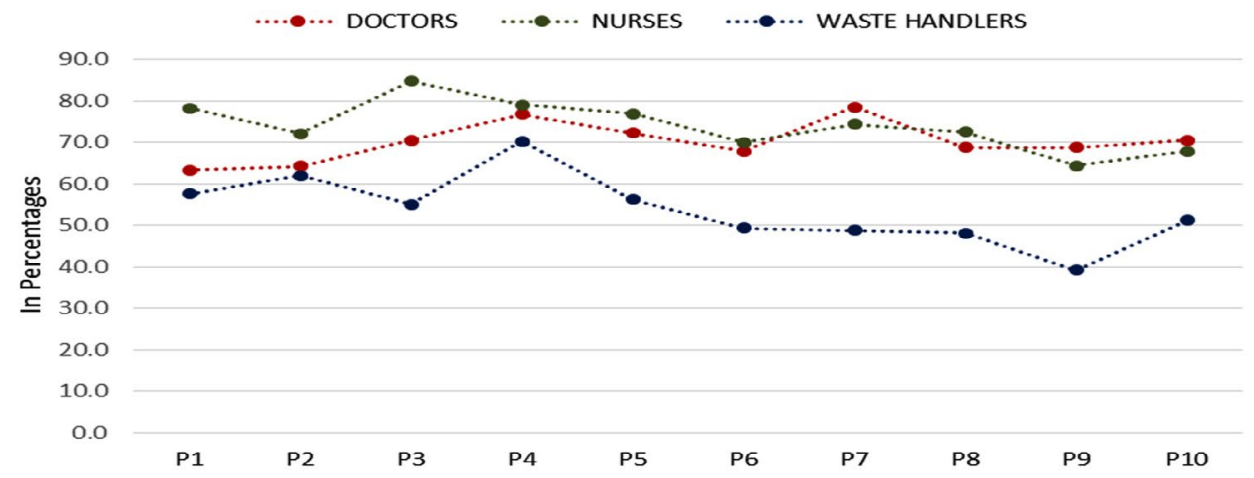

Fig. 2. BMWM adequacy of existing practices among healthcare personnel. 
The difference in level awareness among doctors, nurses, and waste handlers about various aspects of BMWM was found statistically significant with a p-value $<0.05$ (Table 2).

Overall nurses showed maximum adequacy level of existing practices at $74.0 \%$ followed by doctors at $70.2 \%$ and waste handlers at $53.8 \%$ (Table 3, Fig. 2).

On comparing the existing practices among doctors, nurses, and waste handlers, the significant difference in the level of existing practices was found for all the aspects except

Table 2. BMWM awareness among health care personnel

\begin{tabular}{|c|c|c|c|c|c|c|}
\hline & \multirow{2}{*}{$\begin{array}{l}\text { Awareness of Bio Medical Waste } \\
\text { Management as per } 2016 \text { guidelines. }\end{array}$} & \multicolumn{3}{|c|}{ SATISFACTORY AWARENESS } & \multirow[t]{2}{*}{ chi sq } & \multirow[t]{2}{*}{$p$-value } \\
\hline & & $\begin{array}{l}\text { Doctors } \\
(\mathrm{N}=112)\end{array}$ & $\begin{array}{l}\text { Nurses } \\
(\mathrm{N}=230)\end{array}$ & $\begin{array}{c}\text { Waste } \\
\text { Handlers } \\
(\mathrm{N}=158)\end{array}$ & & \\
\hline A1 & Salient guidelines of BMWM Rules & $80(71.4 \%)$ & $164(71.3 \%)$ & $101(63.9 \%)$ & 2.78 & 0.249 \\
\hline $\mathrm{A} 2$ & Significance of Biohazard Symbol & $82(73.2 \%)$ & $170(73.9 \%)$ & $96(60.8 \%)$ & 8.55 & 0.014 \\
\hline A3 & $\begin{array}{l}\text { Percentage of Infectious waste among } \\
\text { total waste in hospital }\end{array}$ & $71(63.4 \%)$ & $144(62.6 \%)$ & $76(48.1 \%)$ & 9.70 & 0.008 \\
\hline A4 & Hazards associated with improper BMWM & $88(78.6 \%)$ & $167(72.6 \%)$ & $102(64.6 \%)$ & 6.61 & 0.037 \\
\hline A5 & Description of PPE while handling BMW & $74(66.1 \%)$ & $149(64.8 \%)$ & $104(65.8 \%)$ & 0.07 & 0.964 \\
\hline A6 & Segregation of BMW at Source & $79(70.5 \%)$ & $158(68.7 \%)$ & $82(51.9 \%)$ & 14.30 & 0.001 \\
\hline A7 & $\begin{array}{c}\text { Color coding of BMW as per } 2016 \\
\text { guidelines }\end{array}$ & $75(67.0 \%)$ & $169(73.5 \%)$ & $73(46.2 \%)$ & 30.80 & $<0.001$ \\
\hline A8 & Storage of BMW beyond 48 hours & $82(73.2 \%)$ & $162(70.4 \%)$ & $87(55.1 \%)$ & 13.10 & 0.001 \\
\hline A9 & $\begin{array}{c}\text { Transportation rules including GPS } \\
\text { system in BMW Vehicles }\end{array}$ & $62(55.4 \%)$ & $146(63.5 \%)$ & $67(42.4 \%)$ & 16.80 & $<0.001$ \\
\hline \multirow[t]{3}{*}{ A10 } & Proper final disposal of waste & $75(67.0 \%)$ & $164(71.3 \%)$ & $96(60.8 \%)$ & 4.71 & 0.095 \\
\hline & Overall awareness & $68.6 \%$ & $69.3 \%$ & $55.9 \%$ & & \\
\hline & & (60.0\%-77.2\% & $63.3 \%-75.3$ & $8.2 \%-63.6 \%)$ & & \\
\hline
\end{tabular}

Table 3. BMWM awareness of existing practices among healthcare personnel

\begin{tabular}{|c|c|c|c|c|c|c|}
\hline & \multirow{2}{*}{$\begin{array}{l}\text { Assessment of BMWM Practices } \\
\text { as per } 2016 \text { guidelines }\end{array}$} & \multicolumn{3}{|c|}{ SATISFACTORY PRACTICES } & \multirow[t]{2}{*}{ chi sq } & \multirow[t]{2}{*}{$\mathrm{p}$-value } \\
\hline & & $\begin{array}{l}\text { Doctors } \\
(\mathrm{N}=112)\end{array}$ & $\begin{array}{l}\text { Nurses } \\
(\mathrm{N}=230)\end{array}$ & $\begin{array}{c}\text { Waste } \\
\text { Handlers } \\
(\mathrm{N}=158)\end{array}$ & & \\
\hline P1 & $\begin{array}{l}\text { Method for segregating collecting human } \\
\text { anatomical waste }\end{array}$ & $71(63.4 \%)$ & $180(78.3 \%)$ & $91(57.6 \%)$ & 20.2 & $<0.001$ \\
\hline P2 & $\begin{array}{l}\text { Method for segregating contaminated linen, } \\
\text { casts, cotton gauze }\end{array}$ & $72(64.3 \%)$ & $166(72.2 \%)$ & $98(62.0 \%)$ & 4.93 & 0.085 \\
\hline P3 & Method for segregating infected plastic wastes & $79(70.5 \%)$ & $195(84.8 \%)$ & $87(55.1 \%)$ & 41.4 & $<0.001$ \\
\hline P4 & Method for segregating general wastes & $86(76.8 \%)$ & $182(79.1 \%)$ & $111(70.3 \%)$ & 4.1 & 0.129 \\
\hline P5 & Method for segregating metallic sharp wastes & $81(72.3 \%)$ & $177(77.0 \%)$ & $89(56.3 \%)$ & 19.3 & $<0.001$ \\
\hline P6 & Method for discarding infectious liquid waste & $76(67.9 \%)$ & $161(70.0 \%)$ & $78(49.4 \%)$ & 18.6 & $<0.001$ \\
\hline P7 & $\begin{array}{l}\text { Method for discarding used disposable } \\
\text { needles/ Use of Needle Cutter }\end{array}$ & $88(78.6 \%)$ & $171(74.3 \%)$ & $77(48.7 \%)$ & 36.3 & $<0.001$ \\
\hline P8 & How to dispose Intact or broken glassware & $77(68.8 \%)$ & $167(72.6 \%)$ & $76(48.1 \%)$ & 25.8 & $<0.001$ \\
\hline P9 & $\begin{array}{l}\text { Practices of reporting of injuries resulting from } \\
\text { improperly disposed biomedical waste }\end{array}$ & $77(68.8 \%)$ & $148(64.3 \%)$ & $62(39.2 \%)$ & 31.7 & $<0.001$ \\
\hline \multirow[t]{3}{*}{ P10 } & Correct management of Spills & $79(70.5 \%)$ & $156(67.8 \%)$ & $81(51.3 \%)$ & 14.4 & 0.001 \\
\hline & OVERALL(AVERAGE) & $70.2 \%$ & $74 \%$ & $53.8 \%$ & & \\
\hline & SATISFACTORY PRACTICES & \multicolumn{2}{|c|}{$(61.7 \%-78.7 \%)(68.3 \%-79.7 \%)$} & $(46.0 \%-61.6 \%)$ & & \\
\hline
\end{tabular}




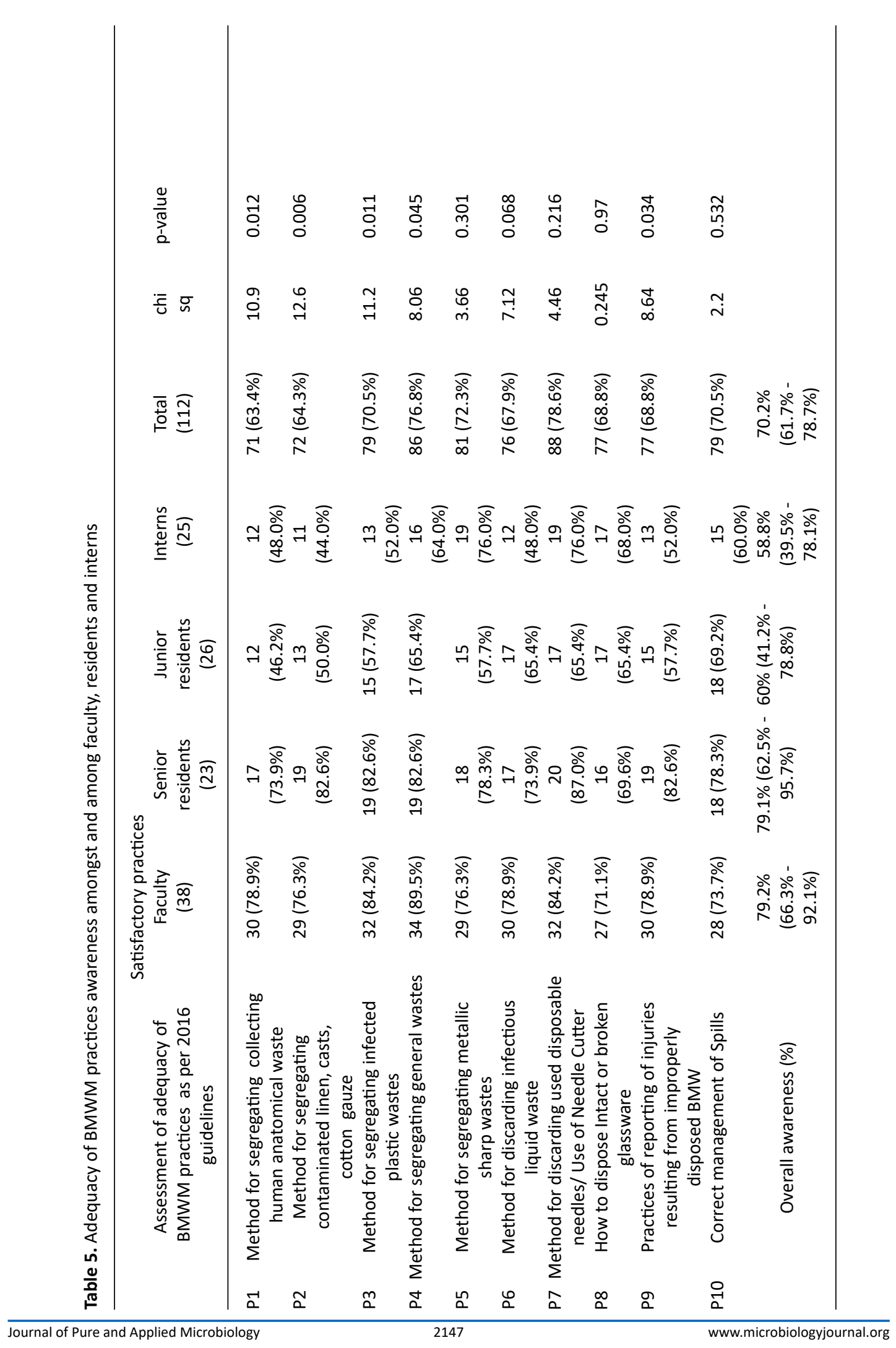


entities like methods for segregating infective non-plastic waste $(p=0.085)$ and method for segregating general wastes $(p=0.129)$.

Faculties showed the maximum level of awareness at $83.4 \%$ and interns showed the minimum level of awareness at $52.0 \%$ (Table 4 , Fig. 3). On comparing the awareness among faculty, residents, and interns, the significant difference in awareness was found in various aspects.

Overall faculty showed maximum compliance with existing practices with an overall rate of $79.2 \%$ while interns' showed an overall $58.8 \%$ practice level. (Table 5, Fig. 4)

\section{DISCUSSION}

BMWM practices are far from optimal in India. The issues in segregation, transport and disposal are major biosafety threats. Inappropriate disposal techniques have reached alarming levels in respect to environmental safety and public health.

India generates about three million tons of medical waste every year. 10 to $35 \%$ of this BMW is potentially hazardous. Inappropriate separationism at point of generation and desultory mingling with non-hazardous waste create a bigger load of hazardous waste..$^{12}$

Various studies in the past have shown that health care workers in our country are still not

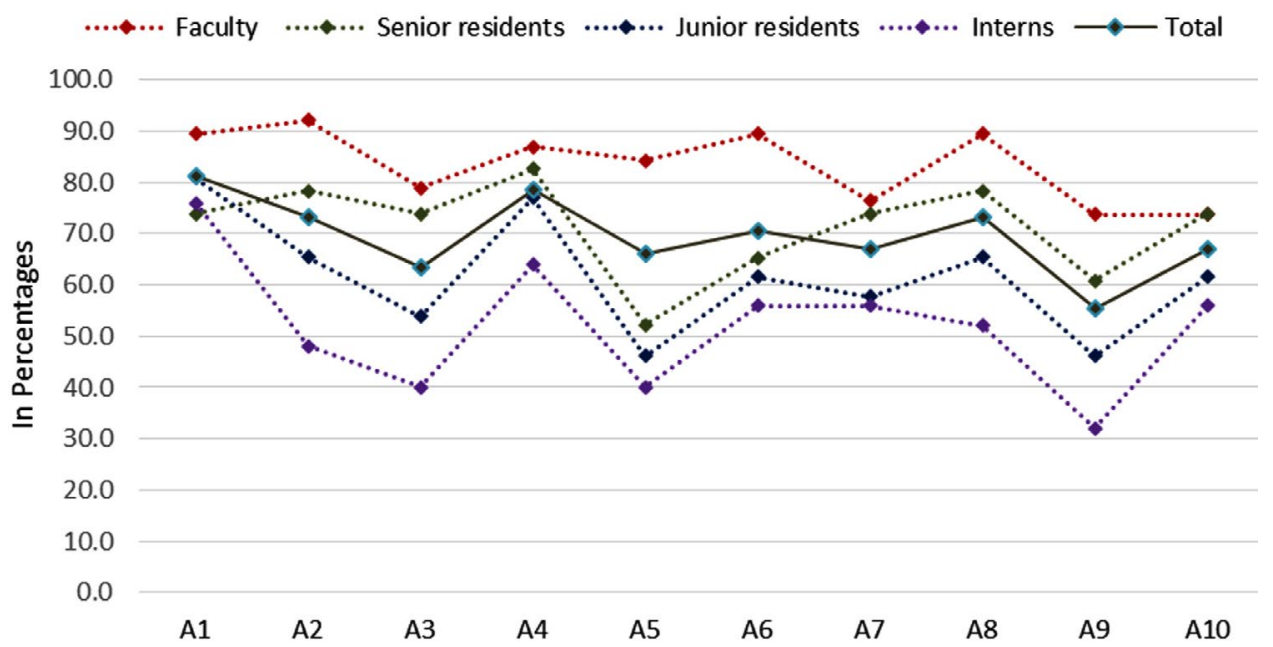

Fig. 3. Level of awareness to BMWM among faculty, residents and interns.

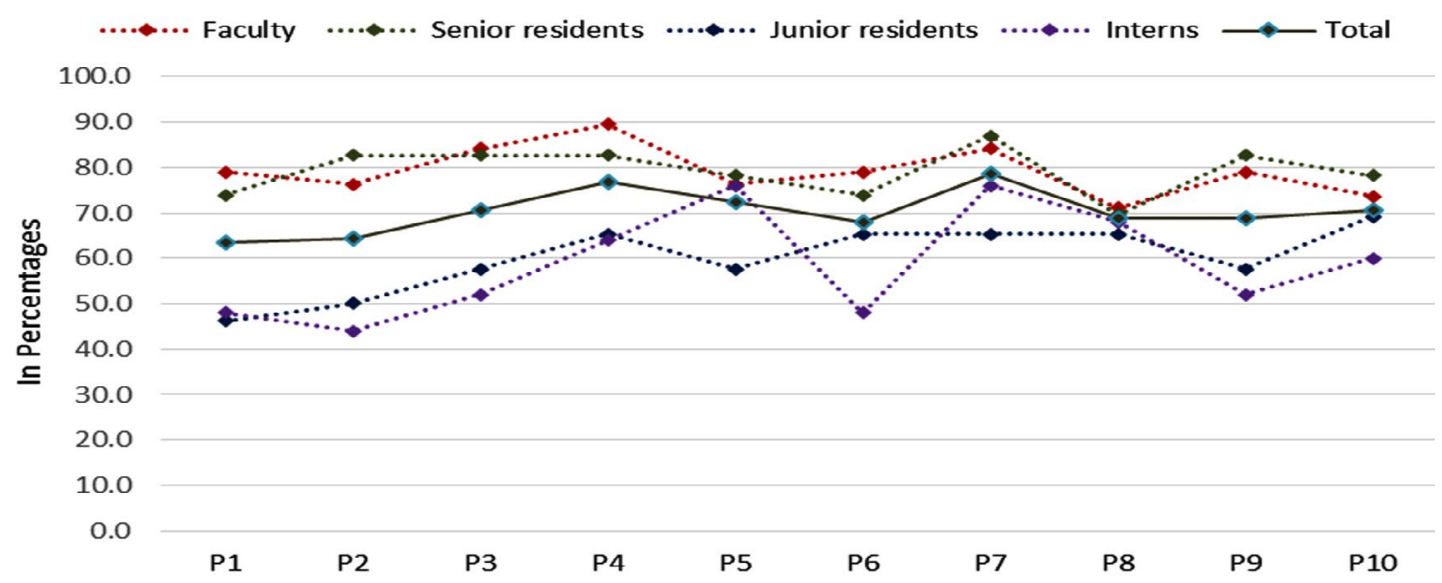

Fig. 4. Level of practices to $B M W$ among faculty, residents and interns. 
fully aware of proper BMW handling and disposal. Although globally there is heightened awareness about proper BMW handling and disposal. ${ }^{13} \mathrm{~A}$ report by the Indian Institute of Management, Lucknow depicted that about $50-55 \%$ of the BMW generated in India is managed properly at all levels of disposal chain while the remaining mostly ends up mixing with the general waste. ${ }^{14}$ Thus heightened awareness, stringent processes, and appropriate skills among health care workers are essential for the adequate management of biomedical waste. Various studies conducted across India revealed gaps in the knowledge, behavioral void, and inconsistent practice which are major roadblocks in proper BMWM..$^{15-16}$

Overall, most groups of HCP scored fairly on BMWM practices awareness. The awareness about BMW among doctors and nurses was relatively better (68.6\% and $69.3 \%$ respectively), followed by that of waste handlers (59.9\%).

The findings are consistent with the study done by a french study, where $62.6 \%$ of HCWs were having adequate knowledge regarding BMWM. ${ }^{17}$ An Indian study found that $64 \%$ of nurses had satisfactory knowledge and awareness regarding BMWM. ${ }^{18}$

The findings in our study could be attributed to the fact that regular BMW training is compulsorily imparted to all doctors, nurses, and waste handlers in the hospital. Additionally, onsite training is giving to all HCWs in the wards by the BMWM team. Online and hybrid modes of training were used during the pandemic.

Need to focus on all categories of healthcare workers are of utmost importance. In our study, we found that $79.4 \%$ of HCWs have attended the BMWM training program of which $79.4 \%$ were doctors and $83 \%$ were nurses. However, only $68.9 \%$ of waste handlers attended the training program. This reflects the low level of awareness and teaching opportunities among the waste handlers.

The gaps in knowledge were seen in BMW aspects regarding segregation, color coding, storage and transport and significance of biohazard symbol and the findings were statistically significant. As these $\mathrm{HCW}$ s are regularly engaged in the process of BMWM, therefore there is an urgent need to sensitize. ${ }^{19}$
Lesser knowledge amongst sanitary staff is mainly attributed to relatively lesser educational qualifications. Kapoor et al in their systematic review concluded that the level of knowledge in the study population regarding BMW was low and continuous training programs were needed to enhance it. ${ }^{20}$

On comparing the awareness and existing practices among faculty, residents, and interns, the level of awareness was higher among faculties as compared to the other doctors. ${ }^{21}$ This could be due to the greater number of training and onsite programs attended by the faculty and senior residents. As most of the interns and junior residents were recently recruited they had missed some of the training programs. Hence continuous training for all newly recruited doctors needs to be organized periodically. There is also a need for online recurrent training on BMWM with short refresher courses.

Though a greater number of doctors and nurses owned BMWM practices, nurse's engagement to best practices was noteworthy. ${ }^{22}$ This could be because of the regular on-site training programs for nursing staff on segregation and transportation. Practices of segregation of plastic waste, metallic waste, and proper use of needle cutters were considerably better in nurses as compared to doctors. Proper discarding of liquid waste and broken glassware was also better known to nurses than doctors. Higher practice compliance scores amongst nursing colleagues could be attributed to better discipline, ownership on BMWM process, answerability and the responsibility bestowed upon them. Injury reporting from improperly disposed of BMW were higher among doctors in comparison to nurses.

Sanitation workers were largely ignorant about most of the aspects of BMWM practices. Most of these sanitation workers were placed on ad hoc jobs and were less aware about biohazard risk from BMW.

Every step involving biomedical waste generation, segregation, storage, transport and disposal need to be closely monitored. A surveillance system needs to be set for ensuring integrity of the whole process. Information, Education and communication (IEC) activities need to be contextual, ongoing and assessment based. 
BMWM training program is essential to sensitize and raise awareness among HCWs. It also emphasizes the importance of the segregation of BMW. The training program also educates about the hazards associated with poor BMWM with special emphasis on sharp injuries.

Training should emphasize on empowering the health professionals on all theoretical and practical aspects of BMWM. Political will, ownership of BMWM, stringent implementation and IEC activities are pivotal in the program. The ramifications of best practices regarding BMWM go beyond realms of biosafety, injury prevention, vaccination, universal precautions. Novel and contextual strategies need to be adapted. Road shows, posters, handouts, stickers, charts and dedicated theme days will raise the awareness. ${ }^{23}$ Active surveillance, checklists and regular audits can enhance accountability in BMWM.

\section{CONCLUSION}

Improper disposal of BMW has many adverse and harmful effects on the environment \& human health. To improve BMWM, it is important to be aware of its proper management and understand and evaluate the current practices in BMWM, to identify the gaps and to address them. Multipronged approach for education and implementation needs to be contextualized utilizing routine and novel tools. Advanced surveillance and checklist based pathways need to be utilized at every level of BMWM.

\section{ACKNOWLEDGMENTS}

I would like to thank Infection Control Nurses for their logistical support. I would also like to express my gratitude towards the BMW team, hospital administration \& staff for their relentless support.

\section{FUNDING}

None.

\section{DATA AVAILABILITY}

The datasets used and/or analysed during the current study are available from the corresponding author on reasonable request.

\section{ETHICS STATEMENT}

It is an observational and noninterventional study. Principles of research ethics have been followed. No human or animal experimentation was involved.

\section{INFORMED CONSENT}

Informed consent was obtained for experimentation and that it confirms to the standards currently applied in India. The privacy rights of participants were observed.

\section{REFERENCES}

1. Safe Management of Wastes from Health-Care Activities. Second Edition. Edited by Chartier Y, Emmanuel J, Pieper U, et al. WHO. 2014. https://www. euro.who.int/_data/assets/pdf_file/0012/268779/ Safe-management-of-wastes-from-health-careactivities-Eng.pdf

2. Bio-Medical Waste (Management and Handling, 1998) Rules. New Delhi: Government of India Publications; Ministry of Environment and Forests Notification; 1998:276-284.

3. Revised Draft Guidelines on Best Available Techniques and Provisional Guidance on Best Environmental Practices of the Stockholm Convention on Persistent Organic Pollutants. Geneva: Secretariat of the Stockholm Convention. Secretariat of the Stockholm Convention. 2006.

4. Anwer M. Solid Waste Management in India Under COVID19 Pandemic: Challenges and Solutions. Int J Eng Res Technol. 2020;9(06):368-373. doi: 10.17577/ IJERTV9IS060079

5. WHO. Review of Health Impacts from Microbiological Hazards in Health-Care Wastes. Geneva: World Health Organization. 2004.

6. Corrao CRN, Mazzotta A, LA Torre G, De Giusti M. Biological Risk and Occupational Health. Industrial Health. 2012;50(4):326-337. doi: 10.2486/indhealth. MS1324

7. Rachiotis G, Papagiannis D, Markas D, Thanasias E, Dounias G, Hadjichristodoulou C. Hepatitis B virus infection and waste collection: Prevalence, risk factors, and infection pathway. Am J Ind Med. 2012;55(7):650655. doi: 10.1002/ajim.22057

8. Mattiello A, Chiodini P, Bianco E, et al. Health effects associated with the disposal of solid waste in landfills and incinerators in populations living in surrounding areas: a systematic review. International Journal of Public Health. 2013;58(5):725-735. doi: 10.1007/ s00038-013-0496-8

9. Khan FA, Soderquist B, Jass J. Prevalence and Diversity of Antibiotic Resistance Genes in Swedish Aquatic Environments Impacted by Household and Hospital Wastewater. Front Microbiol. 2019;10:688. doi: 10.3389/fmicb.2019.00688

10. Padmanabhan KK, Barik D. Health Hazards of Medical 
Waste and its Disposal. Energy from Toxic Organic Waste for Heat and Power Generation. 2019;99-118. doi:10.1016/B978-0-08-102528-4.00008-0

11. Imchen T, Kumari R, Singh JV, Srivastava K, Singh A. Study of biomedical waste management among healthcare personnel at a Tertiary hospital in Lucknow district. Int I Community Med Public Health. 2017;4(5):1483-1487. doi: 10.18203/2394-6040. ijcmph20171460

12. Datta P, Mohi G, Chander J. Biomedical waste management in India: Critical appraisal. J Lab Physicians. 2018;10(1):6-14. doi: 10.4103/JLP. JLP_89_17

13. INCLEN Program Evaluation Network (IPEN) study group, New Delhi, India. Bio-medical waste management: situational analysis \& predictors of performances in 25 districts across 20 Indian States. Indian J Med Res. 2014;139(1):141-153.

14. Mor RS, Sarbjit S, Bhardwaj A, Osama M. Exploring the awareness level of biomedical waste management: Case of Indian healthcare. Management Science Letters. 2017;7:467-478. doi: 10.5267/j.msl.2017.7.004

15. Dudi M, Sharma R, Sharma S, Jain M. Assessment of the knowledge, attitude and practices regarding Biomedical Waste Management amongst Paramedical Staff in a Tertiary Level Health Care Facility. Int J Med Sci Public Health. 2016;5(4):615-619. doi: 10.5455/ ijmsph.2016.1107201594

16. Rajput A, Deshpande K, Chakole SV, Mehta SC. Is Biomedical Waste Management Knowledge Adequate in Paramedics \& Sanitary Workers in Hospitals of Ujjain City. Natl J Community Med. 2016;7(3):151-154
17. Ndiaye P, Fall C, Diedhiou A, Tal-Dial A, Diedhiou O. Gestion des déchets biomédicaux (DBM) au Centre hospitalier régional (CHR) de Ziguinchor [Biomedical waste management in the Regional Hospital Center of Ziguinchor]. Sante. 2003;13(3):171-176.

18. Sharma A, Sharma V, Sharma S, Singh P. Awareness of biomedical waste management among health care personnel in jaipur, India. Oral Health Dent Manag. 2013;12(1):32-40.

19. Hakim SA, Mohsen A, Bakr I. Knowledge, attitudes and practices of health-care personnel towards waste disposal management at Ain Shams University Hospitals, Cairo. East Mediterr Health J. 2014;20(5):347-354. doi: 10.26719/2014.20.5.347

20. Kapoor D, Nirola A, Kapoor V, Gambhir R-S. Knowledge and awareness regarding biomedical waste management in dental teaching institutions in India- A systematic review. J Clin Exp Dent. 2014;6(4):e419-e424. doi: 10.4317/jced.51565

21. Sharma P, Jais M, Gupta P, Randhawa V. Adequacy of awareness regarding biomedical waste management among health care workers in a tertiary care hospital in Delhi. Journal of Patient Safety \& Infection Control. 2015;3(2)98. doi: 10.1016/j.jpsic.2015.10.150

22. Mathur V, Dwivedi S, Hassan M, Misra R. Knowledge, Attitude, and Practices about Biomedical Waste Management among Healthcare Personnel: A Cross-sectional Study. Indian J Community Med. 2011;36(2):143-145. doi: 10.4103/0970-0218.84135

23. Ministry of Environment, Forest, and Climate Change, Biomedical Waste Management Rules, New Delhi; 2016:1-63. 